\title{
Marco Antonio Cruz: la construcción de una mirada (1976-1986)
}

Arturo Ávila Cano

Editor / revista Alquimia-INAH, México

arturoavilacano@gmail.com

Alberto del Castillo Troncoso, Marco Antonio Cruz: la construcción de una mirada (1976-1986), México, CONACYT/Instituto Mora, 2020.

\section{La construcción de una mirada: ensayo y perfil sobre un documentalista}

"Hay que desentrañar, rascar a fondo. [...] hasta encontrar el tejido profundo". Pienso en estos versos que forman parte de la Oda al hombre sencillo del poeta Pablo Neruda, para dar cuenta de la compleja investigación desarrollada tanto en archivos documentales como en acervos fotográficos, y apoyada en decenas de entrevistas que le permitieron al historiador Alberto del Castillo Troncoso trazar un amplio perfil entendido desde el oficio periodístico como un relato donde el autor domina el arte de acomodar las luces sobre un personaje para dar cuenta de su vida y trayectoria profesional-, en este caso sobre el documentalista y fotógrafo Marco Antonio Cruz (1957-2021), que formó parte del nuevo fotoperiodismo mexicano, aquella generación que Ariel Arnal y John Mraz denominaron como de la mirada inquieta.

Del Castillo, reconocido en la academia como un acucioso investigador y tenaz estudioso de la historia de la fotografía mexicana, concretamente de la práctica documental y del periodismo gráfico, prolífico autor que nos ha entregado publicaciones como Rodrigo Moya. Una mirada documental (2011), Pedro Valtierra. Mirada y testimonio (2012) así como Las mujeres de X'OYEP (2013), entre muchos otros textos más incluidos en libros colectivos como Imaginarios y fotografía en México, 1839-1970 (2005), fundamentales para el estudio de esta

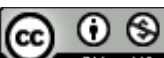

4.0 Internacional

Secuencia. Reseñas, 2021

http://secuencia.mora.edu.mx

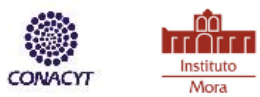


materia, nos ofrece en Marco Antonio Cruz: la construcción de una mirada (19761986), el testimonio de diez años decisivos en la formación ideológica, plástica y técnica de uno de los mejores fotógrafos del último tercio del siglo pasado.

La voluminosa publicación -633 páginas en total-, de pasta suave y formato vertical, contiene tres capítulos con múltiples apartados en los que el autor expone ampliamente su oficio como historiador. Cada uno de ellos contiene una serie de imágenes -cartones políticos, collages o fotografías elaboradas por Marco Antonio Cruz (MAC), así como portadas o recortes de distintas publicaciones en las que colaboró el fotógrafo-. Tanto la narrativa como las imágenes seleccionadas dan cuenta de momentos decisivos en la vida y trayectoria de este profesional de la lente. La portada del libro, cuyo diseño ilustra el diafragma de una cámara, ofrece al lector fragmentos de algunas de las mejores fotografías de MAC. La cantidad de fuentes consultadas para esta magna investigación están a la vista del lector y se encuentran en la parte final de la obra. Entre ellas se citan archivos, comunicaciones personales, entrevistas, ponencias, así como recursos bibliográficos y hemerográficos. Ese aparato crítico va acompañado de un índice onomástico como guía para un lector exigente.

En la introducción, Del Castillo puntualiza que se limitó a investigar la primera década de la vida estudiantil y profesional de Marco Antonio Cruz, etapa en la que trabajó como caricaturista y fotógrafo; sin embargo, también aborda algunos hechos significativos de la infancia y juventud del renombrado fotógrafo. En el segundo capítulo expone el trabajo que MAC realizó para distintas publicaciones periódicas como Sucesos e Interviú en Lucha, y su paso por semanarios de la izquierda comunista o socialista como Oposición y Así Es. El último capítulo concluye con la participación de Marco Antonio Cruz en la agencia Imagenlatina, pero sobre todo en el diario La Jornada. Toda esa información fue adecuadamente contextualizada por el autor quien al respecto indica que el itinerario del fotógrafo por el periodismo se desarrolló en medio de un periodo histórico importante para nuestro país, el tiempo de "la transición política que condujo a la alternancia 
democrática en México", tiempo de cambios culturales y de luchas sindicales que condujeron a la pérdida de la hegemonía del Partido Revolucionario Institucional. "El trabajo periodístico de Marco Antonio Cruz da cuenta de una manera muy personal de esos procesos [...]."

La renuncia de MAC al diario La Jornada acotaba esta amplia investigación; sin embargo, el autor se permitió una licencia para incluir fotografías que fueron realizadas a posteriori cuando el fotógrafo relanzó la agencia Imagenlatina, y combinaba su labor como reportero gráfico independiente, con la realización de diversos proyectos personales a manera de ensayos. Del Castillo justifica la puesta en página de imágenes que están alejadas en tiempo y espacio como un motivo para "sugerir diversas comparaciones y contrastes con imágenes ... realizadas en etapas posteriores”. Es decir, el autor sigue una estrategia de la Historia del arte para crear un "diálogo" entre diversas fotografías mediante sus afinidades y semejanzas iconográficas y al hacerlo compara imágenes dirigidas con instantes propios del periodismo gráfico, resaltando las preocupaciones formales de MAC.

Desde la propia introducción del libro, el autor, adscrito al Instituto de Investigaciones Dr. José María Luis Mora, da cuenta del largo camino que tuvo que transitar. Aborda a detalle aspectos biográficos que ofrecen al lector un amplio panorama sobre distintas etapas de la vida de Marco Antonio Cruz, su ingreso a la Escuela Popular de Arte de la Universidad Autónoma de Puebla, su simpatía por las causas populares, su militancia en el Partido Comunista Mexicano donde trabajó como fotógrafo, así como el contexto sociopolítico en el que creció y ejerció diversos oficios a lo largo de su vida: caricaturista, editor, laboratorista, reportero gráfico y documentalista o ensayista. Además, se detiene en algunas imágenes para subrayar aspectos fundamentales que permitan al lector comprender el discurso iconográfico y las búsquedas temáticas de MAC.

Dada la magnitud de la obra, el autor expone las dos coordenadas que guiaron su trabajo, y el lector encontrará que una de ellas se impone claramente a lo largo del 
libro: "una sincrónica, que tiene que ver con el desarrollo de los trabajos periodísticos enmarcados en sus propios contextos, y la diacrónica, que se refiere a la prolongación en el tiempo de las pulsiones y las intuiciones del autor, las cuales encuentran su desarrollo ulterior y su expresión más lograda en los ensayos fotográficos realizados en décadas posteriores”. El propósito de la obra es muy claro: dilucidar de qué manera se fue construyendo "esa mirada documental muy personal", bajo un estilo que le permitió distinguirse del resto de los fotógrafos de su generación, tanto en el ámbito mexicano como en el latinoamericano.

Es importante señalar que, con el fin de enganchar al lector, en el primer capítulo del libro Del Castillo ensaya un estilo literario y lo combina con los datos duros de la historia; sin embargo, en los siguientes apartados recobra el tono del historiador; así, en el capítulo intitulado "Inicio del viaje", narra con fluidez distintos sucesos que dan cuenta de la complicada infancia y juventud de aquel joven que desde niño tenía inclinaciones por las artes plásticas. En los primeros párrafos, el investigador relata que la ausencia paterna dejó a Juana López y a su niño, que en aquel entonces contaba con escasos siete años y ya mostraba notable habilidad para el dibujo, en la precariedad económica y con diversas carencias materiales. Dicha situación obligó a la señora a trabajar en distintas fábricas textiles.

Más adelante expone el ingreso del joven Cruz a un internado, el apoyo de los vecinos para canalizar sus inquietudes y su aproximación con diversas obras literarias, y su entrada a la Escuela Popular de Arte (EPA) de la Universidad Autónoma de Puebla (1973) cuando contaba con 17 años. De acuerdo con el autor, fue la convocatoria para ingresar a la Escuela Popular de Arte en la ciudad de Puebla, lo que permitió que MAC entrara en contacto con una realidad distinta que modificó para siempre el curso de su historia. Del Castillo expone el difícil contexto histórico en el que surgió aquella institución académica así como el vínculo de distintos artistas egresados de la Academia de San Carlos y la Escuela Nacional de Artes Plásticas de la Universidad Nacional Autónoma de México, algunos de ellos protagonistas de la Gráfica de 1968, que se incorporaron al proyecto y junto con 
Jorge Pérez Vega y Enrique Condes, elaboraron un nuevo plan de estudios, en el que figuraba la enseñanza de la fotografía y la producción gráfica vinculada a los movimientos sociales. En ese ambiente, crispado por luchas políticas y sociales, y caracterizado por la experimentación plástica y el estímulo a la creatividad, se fueron configurando y definiendo los intereses del joven Marco Cruz.

La narrativa creada por Del Castillo permite al lector dimensionar la trascendencia de los eventos ocurridos en la primera etapa de vida de Marco Cruz, que influyeron decididamente en sus afinidades estéticas, ideológicas y políticas, así como en su interés por vincular las artes plásticas con las causas sociales. Fue de la mano de un grupo de profesores entusiastas que alentaban a los jóvenes para asumir un compromiso social, que MAC tuvo su primer contacto con la fotografía. De hecho, las primeras imágenes que logra crear por medio de una cámara son aquellas que hizo con una Yashica $50 \mathrm{~mm}$ de lente fijo que le obsequiara su madre; entre esas imágenes destaca la fotografía sobre tres músicos ambulantes invidentes que captó en la calle 5 de mayo del centro de Puebla. Del Castillo rescata la historia contada por el propio fotógrafo, así como aquella en la que exponía la dificultad para comprender el mecanismo de una cámara.

Ese primer capítulo culmina con distintos sucesos que de algún modo fueron definiendo el camino profesional de Marco Antonio Cruz y que Alberto Del Castillo resume en algunas páginas, a saber el cierre de la EPA y su traslado a la ciudad de México para estudiar en la Escuela de Diseño y Artesanías de la Ciudadela (EDA), en Balderas, sitio que actualmente alberga al Centro de la Imagen; su encuentro con el fotógrafo Rubén Pax Cárdenas, que en aquel entonces trabajaba como maestro de la EDA; su acercamiento con gente del ámbito cultural y con maestros de la fotografía como Héctor y María García, que le invitaron a trabajar para la agencia Foto Press, lugar en el que se desempeñó como laboratorista y auxiliar en diversas faenas administrativas. 
"En la oposición comunista", segundo capítulo del libro, el autor ofrece información puntual sobre eventos de carácter social y político acontecidos en las décadas de los setenta y ochenta del siglo pasado que fueron muy importantes en la vida de Marco Antonio Cruz. Eso le permite contextualizar el perfil del joven fotógrafo que por afinidad ideológica militó en el Partido Comunista Mexicano, al que ingresó en 1981 y en el que trabajó como caricaturista y fotógrafo para los semanarios Oposición y Así es, del Partido Socialista Unificado de México (PSUM). Subraya que "el trabajo de Cruz en Oposición, de septiembre de 1979 a finales de 1981, representó una etapa importante en su formación profesional [...], la cual le permitió ir precisando sus intereses y comenzar un amplio aprendizaje visual en torno a las decisiones editoriales del semanario, que en ocasiones llegaron a desplegar sus imágenes en las primeras planas".

En ese contexto, donde la imagen era apreciada como una ilustración para acompañar las notas o los artículos de los colaboradores, entre los que destacaron Marcela Lagarde, Gilberto Rincón Gallardo, Enrique Semo, Daniel Cazés y Froilán López Narváez, entre otros, Marco Cruz fue construyendo poco a poco un entorno ideal para que la imagen fotográfica cobrara importancia. Fue tal la identificación de aquel joven con los ideales del PCM que nombró al laboratorio que logró montar en las instalaciones del partido como Tina Modotti, fotógrafa y militante comunista. En el libro, hay un autorretrato que da cuenta de ese hecho. En la parte superior de aquel encuadre se aprecia una copia de un retrato de Modotti, elaborado por Edward Weston.

En este capítulo destacan los retratos que MAC hiciera de la luchadora social Rosario Ibarra de Piedra, de marchas como la del 2 de octubre, la del movimiento magisterial, o la que llevaron a cabo campesinos de Chiapas a la ciudad de México en 1983; así como los mítines a favor de la despenalización del aborto, las marchas del Orgullo Homosexual, protestas de trabajadores de sindicatos independientes, y caricaturas en las que satirizaba a los líderes charros y a la política económica del gobierno, entre otros asuntos, además de algunas portadas del semanario Así es, órgano informativo del PSUM. Del Castillo señala que las portadas de ese semanario, 
el "más relevante de la izquierda de principios de los ochenta del siglo pasado constituyeron un espacio privilegiado para la difusión de los trabajos de Cruz," y además fueron la plataforma para la renovación de la fotografía documental y periodística en aquellos años.

Los tópicos que aborda el autor en el capítulo que cierra el libro son numerosos -en total este apartado comprende 263 páginas- y están enmarcados bajo el título Las huellas de La Jornada. Cabe mencionar que aunque en apariencia esta investigación se limitaba a estudiar la primera década en la trayectoria profesional de Marco Cruz (1976-1986), el autor de este amplio trabajo cedió a la tentación de incluir otras historias y otras fotografías que trascienden el periodo de tiempo establecido en el título, ello debido a la relevancia iconográfica y social de algunas imágenes que forman parte de reportajes, ensayos y fotolibros, y que han sido utilizadas como símbolos para hablar de la injusticia o la pobreza en México. Es así como este último capítulo contiene un gran caudal de información que podría haber formado parte de otro volumen en el que se abordaran a fondo los trabajos en los que profundizó el fotógrafo; sin embargo, los títulos de cada uno de los apartados y subapartados permiten que se haga una lectura organizada.

En el primer apartado de este último capítulo el autor expone el tránsito del grupo de fotógrafos de la agencia Imagenlatina al diario La Jornada. Del Castillo menciona los intereses de gremio que fueron el vínculo para que MAC se relacionara con un grupo de fotógrafos como Pedro Valtierra, Luis Humberto González, Fabrizio León y el brasileño Jesús Carlos, quienes, ante el maltrato y el ninguneo que sufrían por parte de los medios tradicionales, decidieron crear una agencia de fotografía independiente para reivindicar los derechos autorales. Fue así como surgió Imagenlatina. Sobre ella, el autor expone que las ideas eran muy románticas, pero poco prácticas. "En muy poco tiempo, la realidad se impuso y ante la falta de clientes y otros problemas de logística, se postergó la idea de darle continuidad a la agencia.” 
Y es en ese difícil contexto, a raíz de una fractura en el diario Unomásuno que se funda La Jornada, gracias a un proyecto impulsado por “Miguel Ángel Granados Chapa, Humberto Musacchio, Carlos Payán y un grupo importante de intelectuales y escritores." Pedro Valtierra fue nombrado jefe del Departamento de fotografía del nuevo periódico e incorporó a todo el equipo de Imagenlatina. Aquel grupo de fotógrafos impulsó una serie de políticas para que la figura del reportero gráfico fuera respetada y además participara en las decisiones editoriales. Del Castillo resalta que dentro de esas políticas se acordó que se otorgara a la imagen fotográfica el $40 \%$ del espacio del diario, además de equilibrar el salario entre reporteros y fotógrafos y reservar los derechos de autoría de las imágenes, así como considerar su participación en las juntas editoriales en las que se seleccionaban las fotografías a ser publicadas. Al poco tiempo, aquel primer equipo de fotógrafos se percató de que la dirección del periódico no iba a considerar del todo aquellas peticiones y renunciaron en conjunto al cabo de dos años.

El segundo apartado comprende diversas representaciones gráficas de la vida cotidiana en ciudad de México, sobre todo de los transeúntes y los que hacen del espacio público su modus vivendi; una serie de fotografías y la puesta en página de algunas de ellas en el diario La Jornada, son una muestra de ello. En Una radiografía del poder, el autor ubicó caricaturas, tiras de negativos y retratos de líderes políticos y sindicales, realizados bajo la mirada crítica de MAC, como aquella imagen en la que el relámpago del desempleo señala a Miguel de la Madrid como el gran responsable o el retrato del expresidente junto a logo del Partido Revolucionario Institucional, que está de cabeza. En este apartado también sobresalen las representaciones de líderes charros como Fidel Velázquez y su sempiterno puro.

Posteriormente, se da paso a algunos reportajes gráficos como la huelga de los vigilantes del metro (1986), las escenas en la desaparecida pulquería La hija de los apaches (1987) o la protesta de las prostitutas que en La Jornada intitularon como "Mitin de las del oficio" (1985), que fue parte de una cobertura colectiva por 
parte de Andrés Garay, Rubén Pax y MAC. Es preciso destacar el espacio que el autor dedicó a la cobertura que Marco Antonio Cruz hizo del terremoto del 19 de septiembre de 1985, donde narra la experiencia vivida por el grupo de fotógrafos de La Jornada y da detalles de la cobertura realizada durante aquellos trágicos días; todo ello se complementa con los valiosos testimonios de MAC que dan cuenta de sus reflexiones y de lo complicado de realizar una cobertura gráfica en medio de tanto dolor. Entre el conjunto de fotografías, destaca la del edificio Nuevo León, de la Unidad Nonoalco Tlatelolco, que se vino abajo por la magnitud del sismo. Fueron muchas horas de cobertura, sin posibilidad de respiro. Marco Antonio "se encontraba tan impresionado que no podía conciliar el sueño, pero en aquella terrible jornada había tomado una de las fotografías más importantes de toda su carrera."

La fotografía, los fotogramas y la puesta en página de la imagen del edificio Nuevo León tanto en el diario La Jornada como en la revista Life y en la revista Arbetaren, de Suecia, así como en libros de Humberto Musacchio y Carlos Monsiváis, son recuperadas y analizadas por el historiador que logra dar cuenta sobre las distintas imágenes publicadas sobre ese suceso.

Tras la cobertura del terremoto, Del Castillo recobra otros trabajos en los que Marco Antonio Cruz logró imágenes memorables que con el tiempo se han transformado en íconos, fácilmente reconocibles por el público amante de la fotografía; uno de ellos es el ritual de la pasión de Cristo en Iztapalapa -evento en el que MAC captó una imagen memorable con los pies del actor que representaba a Judas en primer plano, en un ángulo superior, mientras que al fondo de la escena se ve al resto de los actores y a la gente presenciando dicha teatralización-.

Del Castillo ofrece al lector otras historias, como la cobertura que un pequeño equipo de fotógrafos de La Jornada -Andrés Garay, Marco Cruz y Rubén Pax-, realizó en Nicaragua en 1985 y que se expuso en el Museo de Arte Moderno de la ciudad de México, pero es en el apartado intitulado Ensayos visuales donde lanza 
una interesante hipótesis; es decir, para el autor aquella línea de trabajo impulsada por aquel diario representó "uno de los espacios más importantes para que el fotógrafo mostrara su vocación como narrador de historias, las cuales constituyen una de sus aportaciones más importantes al fotoperiodismo de aquellos años." "La fotografía transita aquí por un proceso de edición y depuración en el que la imagen ya no depende del texto, conquista una cierta autonomía y proyecta su mayor potencial expresivo y su capacidad de condensación simbólica a partir de relatos que se vinculan con proyectos personales del autor." Entre esos "ágiles proyectos", menciona los trabajos "De libertades", "Apañe", "Concierto en Bellas Artes" y "Cortadores de caña". El autor narra los pormenores de cada uno de ellos, incluye algunas imágenes y analiza tanto el discurso iconográfico presente, como la puesta en página de estas. Es interesante el estudio que lleva a cabo sobre las decisiones del fotógrafo en la construcción de las imágenes en la serie titulada "Apañe", donde es visible la fabricación del culpable en las procuradurías, donde los sujetos se veían obligados a posar con armas que colocaban junto a sus rostros o que dirigían hacia las cámaras, bajo las órdenes de los fotógrafos presentes.

La renuncia colectiva a La Jornada marca el final del libro. Los detalles de aquellos días en los que Pedro Valtierra se presentó como candidato de un grupo para hacerse cargo de la secretaría del sindicato de trabajadores de ese diario, así como las pugnas internas y la animadversión que se generó entre fotógrafos y directivos, así como la renuncia de algunos colaboradores, son expuestas por Del Castillo, que pone a disposición del lector declaraciones y hechos que dan cuenta de las graves fisuras al interior de esa publicación periódica. Un grupo de reporteros gráficos conformado por Herón Alemán, Andrés Garay, Arturo Fuentes, Rubén Pax, Pedro Valtierra y Marco Antonio Cruz decide retomar la agencia Imagenlatina. El apoyo de Miguel Ángel Granados Chapa y José Luis Becerra fue fundamental en ese tránsito. Algunos eventos en torno a la refundación de la agencia fueron rescatados por el autor y están representados en cuatro fotografías. 
Alberto Del Castillo ofrece en diez páginas sus reflexiones finales sobre este amplio trabajo de investigación que demandó varios años de trabajo, etapa en la que continuó su trayectoria como académico, curador, ponente, tutor y responsable, junto con la doctora Monroy Nasr, del seminario de La Mirada Documental, generoso espacio de encuentro donde maestros y estudiantes de la fotografía exponen sus trabajos y sus avances.

Esta es indudablemente una de las investigaciones más complejas en torno a la trayectoria de un fotógrafo cuyos intereses y cuyo trabajo trascendieron la cobertura gráfica de las agendas de los medios informativos, de tal modo, es comprensible que el lector encuentre un aproximado de 280 imágenes: cartones políticos, fotografías, fotogramas, hojas de contacto y diversos recortes o portadas de publicaciones periódicas que dan cuenta del copioso periplo de MAC por la fotografía documental y periodística, y es aquí precisamente donde se encuentra el punto débil de la obra y que corresponde más a un trabajo fino de edición; es decir, el contraste tonal de muchas imágenes tiende a lo monocromático, predominan los grises; asimismo el ruido presente en algunos fragmentos de páginas periodísticas, los recortes sobre algunas imágenes y el tamaño y la ubicación de las mismas, impide no sólo el disfrute visual sino la comparación de la fotografía con su puesta en página. Esto no es peccata minuta si consideramos las búsquedas estéticas que llevaba a cabo el fotógrafo. 